\title{
BMJ Open Does a quality management system improve quality in primary care practices in Switzerland? A longitudinal study
}

Katja Goetz, ${ }^{1}$ Sigrid Hess, ${ }^{2}$ Marianne Jossen, ${ }^{2}$ Felix Huber, ${ }^{3}$ Thomas Rosemann, ${ }^{4}$ Marc Brodowski, ${ }^{5}$ Beat Künzi, ${ }^{6}$ Joachim Szecsenyi ${ }^{1,5}$

To cite: Goetz K, Hess S, Jossen M, et al. Does a quality management system improve quality in primary care practices in Switzerland? A longitudinal study. BMJ Open 2015;5:e007443. doi:10.1136/bmjopen-2014007443

- Prepublication history for this paper is available online. To view these files please visit the journal online (http://dx.doi.org/10.1136/ bmjopen-2014-007443).

Received 12 December 2014 Revised 17 February 2015 Accepted 17 March 2015

CrossMark

For numbered affiliations see end of article.

Correspondence to Dr Katja Goetz; katja.goetz@ med.uni-heidelberg.de

\section{ABSTRACT}

Objectives: To examine the effectiveness of the quality management programme-European Practice Assessment-in primary care in Switzerland.

Design: Longitudinal study with three points of measurement.

Setting: Primary care practices in Switzerland.

Participants: In total, 45 of 91 primary care practices completed European Practice Assessment three times.

Outcomes: The interval between each assessment was around 36 months. A variance analyses for repeated measurements were performed for all 129 quality indicators from the domains: 'infrastructure', 'information', 'finance', and 'quality and safety' to examine changes over time.

Results: Significant improvements were found in three of four domains: 'quality and safety' ( $F=22.81, p<0.01)$, 'information' ( $F=27.901, p<0.01)$ and 'finance' $(F=4.073, p<0.02)$. The 129 quality indicators showed a significant improvement within the three points of measurement $(F=33.864, p<0.01)$.

Conclusions: The European Practice Assessment for primary care practices thus provides a functioning quality management programme, focusing on the sustainable improvement of structural and organisational aspects to promote high quality of primary care. The implementation of a quality management system which also includes a continuous improvement process would give added value to provide good care.

\section{INTRODUCTION}

The assessment of quality in medical settings is increasingly important for different reasons such as reducing adverse events, optimising efficiency and enhancing patient satisfaction. ' Since the publication of 'To err is human', 2 many healthcare systems concentrate on reducing medical errors and improving patient safety. Thereby, the organisation of care, including structure and process, plays an important role to ensure good

\section{Strengths and limitations of this study}

- The European Practice Assessment is a tool for improving structure and process of primary care.

- A broad set of validated quality indicators were evaluated which focus on structure and process of primary care.

- A continuous implementation of a quality management system for primary care practices was analysed.

- This is a longitudinal follow-up with Swiss primary care practices that completed three points of measurement.

- The study was uncontrolled and a self-selection bias of practices was determined.

quality of care and to improve outcomes of care. ${ }^{3} 4$ The measurement and assessment of structure, process and outcome of care can lead to the implementation of a high-quality management programme.

Therefore, the continuous assessment of quality of care has become an integrated part of healthcare management and has led to a variety of quality improvement initiatives in most healthcare systems. ${ }^{5}$ The improvement process should be ongoing (eg, through plan-do-study-act cycles $^{6}$ ): each step is reviewed and redesigned with a view to improve the quality of the end product, thereby fostering continuous improvement. ${ }^{7}$

In Switzerland, in 1994, regulations related to the quality of care were enshrined in the health insurance act. ${ }^{8}$ However, a definition of quality management, approaches or instruments was not given. Since this time, the measurement of quality in healthcare, including the implementation of quality management programmes, increased. Today, there exist a high number of quality initiatives in Switzerland among different healthcare providers, with very diverse coverage and different thematic focuses. ${ }^{9}$ For primary 
care practices, four different quality initiatives are particularly available. An overview is given by Cassis et al. ${ }^{10}$ To our knowledge, until now no data have been published for these different quality initiatives.

One of the quality initiatives in the ambulatory domain is the EQUAM Foundation which offers the quality management programme European Practice Assessment. ${ }^{11}$ This quality management programme is a comprehensive, integrative and multifaceted tool for quality assessment and quality improvement in healthcare. The strategy has three essential components: assessment and feedback using validated instruments based on quality indicators; external support through an outreach educational visit by a trained auditor (healthcare professionals) to support the practice in improving areas of management identified by the practice itself; and formal certification by an external organisation. ${ }^{12} 13$ Certification is one method for assessing and benchmarking the performance of a practice across a broad range of clinical and organisational indicators. It is a formal process and results in recommendations for continuous improvement of quality in the practice. In Switzerland, the assessment is done by auditors who are independent from the EQUAM Foundation, with the latter taking the role of organising the assessments and certifying the practices. ${ }^{11}$

The systematic measurement of process, structure and outcome of care should result in a continuous improvement process to ensure quality of care. The European Practice Assessment tool has already shown effectiveness in improving the management of general as well as dental care practices in Germany. ${ }^{14-16}$ Unfortunately, there are no available studies about continuous quality improvement in ambulatory primary care in Switzerland. Given the scientific nature of the accompanying research regarding the impact of the continuous process of European Practice Assessment, the current study focuses on the implementation and repeated measurement of a quality management programme for primary care practices-the European Practice Assessment tool -and examined whether the improvements in primary care practices that completed the European Practice Assessment is a continuous repetitive process.

\section{METHODS}

\section{European Practice Assessment}

In Switzerland, the European Practice Assessment is organised by the EQUAM Foundation, based in Berne, which is engaged in external quality control for ambulatory care since $1999 .{ }^{11}$ The European Practice Assessment indicators have been adapted to the Swiss context, the members of the scientific advisory board on standards and indicators are composed of experts in quality management, medical practitioners and medical experts. These different indicators are framed within five key conceptual domains: 'quality and safety', 'infrastructure', 'information', 'finance' and 'people'.
The quality indicators represent different aspects of structure and process of care. For more information of these different indicators use Götz et al. ${ }^{15}$ The practices that process through the European Practice Assessment have either made contact with EQUAM on their own initiative or are requested to take part in the European Practice Assessment by the networks or managed care organisations that they are members of. In some cantons, practices are obliged to install a quality management system of their choice in order to get the authorisation to run a medical practice. As soon as the doctor's offices enrol for European Practice Assessment, questionnaires for patients and staff are provided. The office also can begin to prepare relevant material for the supervision by an auditor who is independent from the office and the EQUAM Foundation. As a consequence of the audit, goals for the coming year are formulated. Furthermore, an anonymous comparison between the office's own practice score and scores of all the other practices that have undertaken the assessment is available through the software called Visotool. Moreover, it serves as a catalyst for quality improvement and for benchmarking.

Under the condition that European Practice Assessment has been successfully completed, a certificate is then issued by EQUAM to the practice. The certificate is valid for 3 years. The costs for a certificate for 3 years for a single or double office add up to about 4200 Swiss Franc. The seriousness of the certificate and the processes accompanying it is guaranteed by the accreditation of the foundation EQUAM by the Swiss Federal Accreditation Service and respect for the recommendations for certification in medical contexts, dressed by the Swiss Academy of Medical Sciences. ${ }^{17}$ In summary, the European Practice Assessment consists of a set of international validated quality indicators for external and internal assessment, and includes the following steps:

1. Patient and staff survey;

2. An outreach visit by an auditor;

3. Structured feedback during a team meeting in the practice with the auditor;

4. Formal certification by an external organisation which will be valid for 3 years. ${ }^{13}$

\section{Design and participants}

The study conforms to the SQUIRE-Guidelines (Standards for Quality Improvement Reporting Excellence). ${ }^{18}$ A longitudinal study design was used. Primary care practice can voluntarily decide to use European Practice Assessment. For this study, primary care practices in Switzerland were included that had completed the European Practice Assessment, as a part of a quality management programme for primary care, three times-as first assessment (T1), reassessment (T2) and re-reassessment (T3). Ninety-one practices had decided to implement the European Practice Assessment. This was the first assessment for these practices. After 3 years, the primary care practices can voluntarily decide 
to repeat the whole process of European Practice Assessment. From the 91 practices at first assessment, 45 practices completed three assessments between 2005 and 2013. The European Practice Assessment is a continuous repetitive process with an interval between each assessment of 36 months. Presently, three cycles from 45 primary care practices are available for data analyses. Figure 1 shows a flow chart of our sample.

\section{Statistical analysis}

The analyses were performed using SPSS V.20.0 (SPSS Inc., IBM). Continuous data were summarised using means and SDs. Categorical data were presented as frequency counts and percentages. The baseline characteristics of practices (T1) were compared with the follow-up practices which participated three times (T3) on the European Practice Assessment using $\chi^{2}$ test and Student $\mathrm{t}$ test. Mean scores of each domain and dimension were calculated, and were based on proportion of indicators for which a positive response was achieved by all of the practices, on a scale of $0-100$. A change of more than five points was considered as a relevant change when comparison was done with other quality improvement studies. ${ }^{14}{ }^{16}$ Furthermore, variance analyses for repeated measurements were performed. The participating practices were compared by considering the time effect over three measurement points. We decided to exclude the domain 'people' from the analysis because these are individual data. It cannot specify whether the same patients take part in the three points of measurement. Furthermore, these data will be discussed in a separate

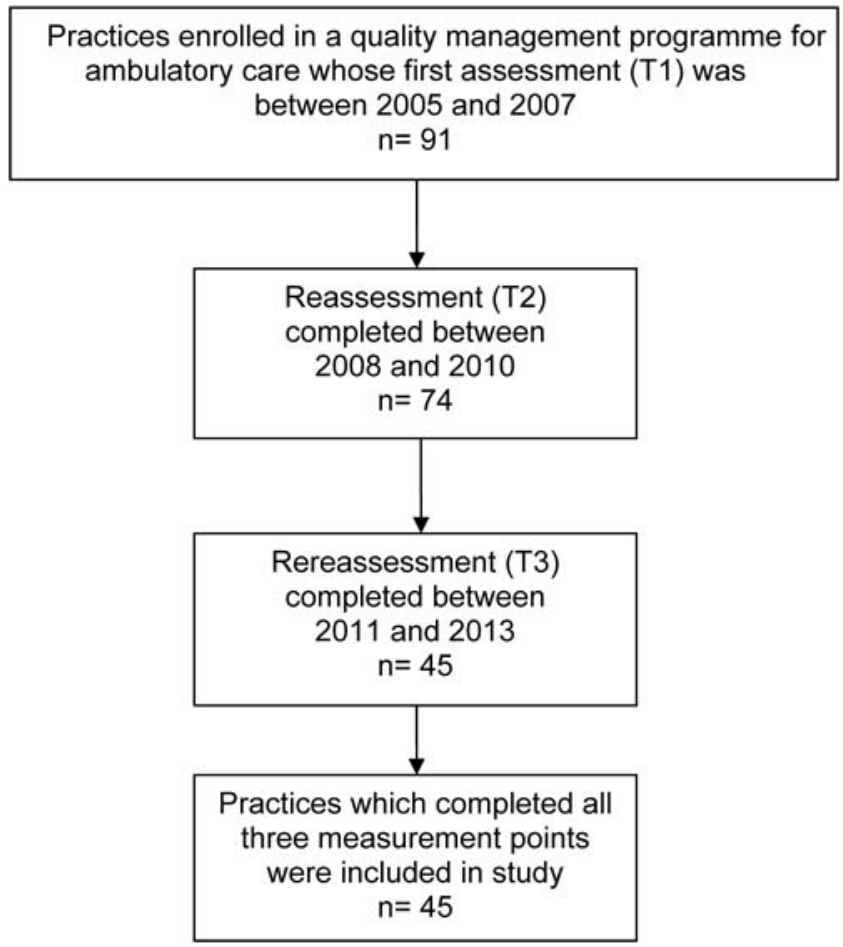

Figure 1 Selection of primary care practices. publication. An $\alpha$ level of $\mathrm{p}<0.05$ was used for tests of statistical significance.

\section{Ethical approval}

Ethical approval was not required because we used secondary data available from the routine implementation of a quality management programme in primary care in Switzerland. ${ }^{8}$ All elements of the European Practice Assessment and the information from the trained external facilitators were anonymised for data analysis in our study. No additional information or data from patients or staff were collected.

\section{RESULTS}

In total, 45 of 91 primary care practices completed the European Practice Assessment three times. The characteristics and the comparison between baseline and follow-up group of primary care practices are listed in table 1.

For analysing longitudinal effects, only practices that completed all three measurements were included in the variance analyses of repeated measurements. Changes in the scores for the domains and all dimensions for the 45 primary care practices at the three measurement times are shown in table 2. When a higher score occurred over three times in all four domains, significant improvements were found in the domains 'quality and safety' $(\mathrm{F}=22.81 ; \mathrm{p}<0.01)$, 'information' $(\mathrm{F}=27.901 ; \mathrm{p}<0.01)$ and 'finance' $(\mathrm{F}=4.073, \mathrm{p}=0.02)$.

\begin{tabular}{|c|c|c|c|}
\hline \multirow[b]{2}{*}{ Characteristics } & \multicolumn{2}{|c|}{ Primary care practices } & \multirow[b]{2}{*}{ p Value* } \\
\hline & $\begin{array}{l}\text { Baseline } \\
(T 1) \\
(n=91)\end{array}$ & $\begin{array}{l}\text { Follow-up } \\
\text { group (T3) } \\
(\mathrm{n}=45)\end{array}$ & \\
\hline \multicolumn{4}{|l|}{$\begin{array}{l}\text { Mode of practice; } \\
\mathrm{n}(\%)\end{array}$} \\
\hline Single & $52(57.1)$ & $22(48.9)$ & 0.46 \\
\hline Group & $37(40.7)$ & $22(48.9)$ & \\
\hline Missing & $2(2.2)$ & $1(2.2)$ & \\
\hline \multicolumn{4}{|c|}{$\begin{array}{l}\text { Location of practice; } \\
n(\%)\end{array}$} \\
\hline Urban & $37(40.7)$ & $10(22.2)$ & 0.05 \\
\hline Rural & $52(57.1)$ & $32(71.1)$ & \\
\hline Missing & $2(2.2)$ & $3(6.7)$ & \\
\hline \multicolumn{4}{|l|}{ Number of GPs } \\
\hline Mean & 2.0 & 2.6 & 0.29 \\
\hline SD & 2.1 & 3.4 & \\
\hline Range & $1-15$ & $1-19$ & \\
\hline \multicolumn{4}{|c|}{$\begin{array}{l}\text { Number of practice } \\
\text { assistants }\end{array}$} \\
\hline Mean & 3.8 & 5.4 & 0.02 \\
\hline SD & 2.2 & 5.8 & \\
\hline Range & $1-13$ & $1-32$ & \\
\hline
\end{tabular}


Table 2 Mean scores for the domains and dimensions of the European Practice Assessment instrument

\begin{tabular}{|c|c|c|c|c|c|}
\hline Domains and dimension* & $\begin{array}{l}\text { Number of } \\
\text { indicators }\end{array}$ & $\begin{array}{l}\text { T1 } \\
(n=45)\end{array}$ & $\begin{array}{l}\mathrm{T} 2 \\
(\mathrm{n}=45)\end{array}$ & $\begin{array}{l}\text { T3 } \\
(n=45)\end{array}$ & $\begin{array}{l}\text { Time effect } \\
\mathbf{F}(\mathbf{p} \text { value }) \dagger\end{array}$ \\
\hline Quality and safety & 44 & 77.6 & 86.2 & 88.4 & $22.81(<0.01)$ \\
\hline Complaint management & 5 & 66.7 & 88.9 & 99.3 & $19.72(<0.01)$ \\
\hline Analysis of critical incidents & 3 & 83.0 & 92.6 & 99.7 & $8.726(0.01)$ \\
\hline Labour & 4 & 89.7 & 93.1 & 89.2 & $1.200(0.31)$ \\
\hline Safety of staff and patients, hygiene, infection control & 17 & 97.6 & 95.8 & 98.2 & $0.617(0.54)$ \\
\hline Quality development, quality policy & 9 & 65.2 & 68.8 & 77.0 & $9.358(<0.01)$ \\
\hline Detection of quality and safety problems & 6 & 67.0 & 78.2 & 75.9 & $4.173(0.02)$ \\
\hline Infrastructure & 34 & 67.3 & 70.9 & 71.8 & $1.822(0.17)$ \\
\hline Accessibility and availability & 6 & 78.6 & 82.8 & 83.7 & $1.196(0.31)$ \\
\hline Disabled access & 4 & 68.7 & 73.4 & 72.9 & $0.463(0.63)$ \\
\hline Premises & 6 & 91.5 & 93.0 & 94.0 & $0.469(0.63)$ \\
\hline Medical equipment including drugs & 12 & 44.1 & 55.7 & 56.7 & $3.675(0.03)$ \\
\hline Non-medical equipment & 1 & 27.3 & 22.7 & 22.7 & $0.138(0.87)$ \\
\hline IT security & 5 & 93.8 & 98.4 & 99.3 & $1.411(0.25)$ \\
\hline Information & 43 & 72.3 & 75.7 & 85.5 & $27.901(<0.01)$ \\
\hline Confidentiality and privacy & 2 & 70.6 & 65.0 & 79.1 & $7.653(<0.01)$ \\
\hline Prevention & 3 & 45.2 & 50.4 & 68.1 & $3.565(0.04)$ \\
\hline Clinical data, patient records & 11 & 79.9 & 79.9 & 85.1 & $1.639(0.21)$ \\
\hline Information for staff & 3 & 96.3 & 92.6 & 95.6 & $0.827(0.44)$ \\
\hline Information for patients on medical care & 3 & 67.4 & 77.8 & 81.5 & $3.671(0.03)$ \\
\hline Use of computers & 4 & 80.0 & 78.3 & 85.6 & $1.706(0.19)$ \\
\hline Communication with other healthcare providers & 6 & 84.4 & 91.9 & 91.9 & $2.747(0.08)$ \\
\hline $\begin{array}{l}\text { Information for patients on practice, practice policy and } \\
\text { community resources }\end{array}$ & 11 & 30.6 & 43.0 & 52.0 & $6.535(0.01)$ \\
\hline Finance & 8 & 71.2 & 75.6 & 81.4 & $4.073(0.02)$ \\
\hline Financial leadership and responsibilities & 4 & 93.3 & 97.8 & 98.9 & $3.470(0.04)$ \\
\hline Financial planning & 1 & 28.9 & 28.9 & 49.0 & $2.633(0.08)$ \\
\hline Annual report (retrospective) & 3 & 91.5 & 100 & 96.3 & $6.863(0.01)$ \\
\hline Total & 129 & 76.9 & 81.2 & 88.2 & $33.864(<0.01)$ \\
\hline
\end{tabular}

\section{Domain: quality and safety}

For the domain 'quality and safety', significant improvements over the three points of measurement were observed in the dimensions 'complaint management' $(\mathrm{F}=19.72 ; \quad \mathrm{p}<0.01)$, 'analysis of critical incidents' $(\mathrm{F}=8.726 ; \mathrm{p}=0.01)$, 'quality development, quality policy' $(\mathrm{F}=9.358 ; \mathrm{p}<0.01)$, and 'detection of quality and safety problems' $(\mathrm{F}=4.173 ; \mathrm{p}=0.02)$.

\section{Domain: infrastructure}

For the domain 'infrastructure', significant improvements were observed over the three points of measurement within the dimension 'medical equipment' $(\mathrm{F}=3.675 ; \mathrm{p}=0.03)$.

\section{Domain: information}

For the domain 'information', significant improvements were observed over the three points of measurement in the dimensions 'confidentiality and privacy' $(\mathrm{F}=7.653$; $\mathrm{p}<0.01)$, 'prevention' $(\mathrm{F}=3.565 ; \mathrm{p}<0.04)$, 'information for patients on medical care' $(\mathrm{F}=3.671, \mathrm{p}=0.01)$, and 'information for patients on practice, practice policy and community resources' $(\mathrm{F}=6.535, \mathrm{p}=0.01)$.

\section{Domain: finance}

For the domain 'finance', significant improvements were evaluated over the three points of measurement in the dimensions 'financial leadership and responsibilities' $(\mathrm{F}=3.470, \mathrm{p}=0.04)$ and 'annual report' $(\mathrm{F}=6.863, \mathrm{p}=0.01)$.

Overall, a significant improvement were observed for all 129 indicators from the four domains of the European Practice Assessment over the three points of measurement $(\mathrm{F}=33.864, \mathrm{p}<0.01)$.

\section{DISCUSSION}

To our knowledge, this was a first study evaluating quality improvement through the continuous implementation of a quality management system in primary care practices in Switzerland.

The comparison of practice characteristics between baseline and follow-up group demonstrated a significant difference regarding the number of practice assistants. It could be assumed that practices which performed the European Practice Assessment three times are larger in terms of personnel resources. The variance analyses with repeated measurements over three time points showed significant improvements in three of four domains as well as for all the 129 indicators. As for the domain of 
infrastructure, it is the only one where no significant improvement could be achieved. This could be due to the fact that many of the measures to be taken in this regard (eg, disabled access) would require major investments. Still, the dimension of medical equipment has shown a significant improvement. The European Practice Assessment shows effects on an area that is also identified as a major thread to patient safety by the practitioners themselves. ${ }^{19}$ In the domain of quality and safety, we observed significant improvements in four of the six dimensions ('complaint management', 'analysis of critical incidents', 'quality development, quality policy', and 'detection of quality and safety problems'). Similar results were reported in a study with primary care practices in Germany. ${ }^{14}$ The European Practice Assessment, thus, shows effectiveness in a further important area of quality: complaint management and analysis of critical incidents are important dimensions to provide patient safety in care and these help to identify problems in this type of care. ${ }^{20}$

Moreover, in the domain of information, we observed significant improvements in dimensions that provide an important basis for communication with patients and thus, also for the safety of patients ('confidentiality and privacy', 'prevention', 'information for patients on medical care', and 'information for patients on practice, practice policy and community resources').

Therefore, our results demonstrate that the amelioration of patient safety, representing a key component of quality management in medicine, is an integral and effective part of the European Practice Assessment. Moreover, the present study confirms the results of the few available studies which consider longitudinal effects of ongoing quality improvement processes and demonstrate that quality improvement needs to be realised via a processual framework over time. ${ }^{14162122}$

Well-organised and safe practices are not only important for healthcare providers, but also for patient care. Furthermore, the fact that the participating practices completed the whole procedure of European Practice Assessment three times indicates an investment in their own quality development and quality policy. Overall, our results demonstrated that patient safety, especially within the domain 'quality and safety' and 'information', is an integral part of the European Practice Assessment and this is one key component of quality of care. ${ }^{23}$

Quality of care requires a mix of objective and subjective measures. ${ }^{24}$ For the measurement, different perspectives should be considered because quality improvement requires a combination of educational, organisational and financial approaches. ${ }^{25}$ In order to start a continuous improvement process with a quality management programme, the intrinsic motivation of practices is only one precondition. Moreover, external incentives, such as a certification through a formal accreditation process, could increase the interest to participate in a quality management programme but could also influence positively the outcome of care. ${ }^{26} 27$

\section{Limitations}

Our study has some limitations. The sample of participating practices was small and may not have been representative of primary care practices in Switzerland. Moreover, we involved only practices that elected to use the European Practice Assessment and who had three points of measurement. Like the other studies that used the European Practice Assessment tool to examine its effectiveness, no comparative group was included in the current study. ${ }^{1416}$ This study was the first of its kind in Switzerland with an observation over a time period of 6 years. However, external validity cannot be addressed as well when compared with the effectiveness of other quality management systems for primary care in Switzerland. Furthermore, potential reasons to decide against continuation of European Practice Assessment were not evaluated. Therefore, the results of the study have to be interpreted carefully and need to be confirmed in further studies. In addition, although it is known that a multifaceted quality management programme motivates practices to change, ${ }^{28}$ there is no reliable evidence from this study about the impact on clinical outcomes because the data presented concentrate on structures and processes of care. The study design was explorative. The observed effects should be examined in further studies with a larger sample.

\section{CONCLUSIONS}

Our findings showed the importance of continuous quality improvement processes in the context of practice assessment, the evaluation of structure and process of care, especially for patient safety. The European Practice Assessment for primary care practices thus provides a functioning quality management programme, focusing on the sustainable improvement of structural and organisational aspects to promote high quality of primary healthcare. As our results showed that an implementation of a quality management system, which also includes a continuous improvement process, would have an added value in providing a systematic performance monitoring of primary care practices.

\section{Author affiliations}

${ }^{1}$ Department of General Practice and Health Services Research, University of Heidelberg, Heidelberg, Germany

${ }^{2}$ EQUAM-Stiftung, Bern, Switzerland

${ }^{3}$ mediX Gruppenpraxis, Zürich, Switzerland

${ }^{4}$ Institute of General Practice and Health Services Research, University of Zürich, Zürich, Switzerland

${ }^{5}$ AQUA-Institute for Applied Quality Improvement and Research in Health Care, Göttingen, Germany

${ }^{6}$ Swisspep Institut für Qualität und Forschung im Gesundheitswesen, Bern, Switzerland

Acknowledgements The authors thank the primary care practices and outreach facilitators who participated in the study.

Contributors KG, SH, FH, BK and JS initiated and designed the study. MB and $\mathrm{SH}$ coordinated the study. KG carried out data analysis and wrote the manuscript. All authors (KG, SH, MJ, FH, TR, MB, BK and JS) read earlier 
versions of the manuscript, provided critical comments and approved the final manuscript.

Funding This research received no specific grant from any funding agency in the public, commercial or not-for-profit sectors.

Competing interests None declared.

Provenance and peer review Not commissioned; externally peer reviewed.

Data sharing statement No additional data are available.

Open Access This is an Open Access article distributed in accordance with the Creative Commons Attribution Non Commercial (CC BY-NC 4.0) license, which permits others to distribute, remix, adapt, build upon this work noncommercially, and license their derivative works on different terms, provided the original work is properly cited and the use is non-commercial. See: http:// creativecommons.org/licenses/by-nc/4.0/

\section{REFERENCES}

1. The Institute of Medicine. Crossing the quality chasm: a new health system for the 21st century. Washington, DC: National Academies Press, 2001.

2. Kohn LT, Corrigan J, Donaldson MS. To err is human: building a safer health system. Washington, DC: National Academic Press, 2000.

3. Ose D, Freund T, Kunz CU, et al. Measuring organizational attributes in primary care: a validation study in Germany. J Eval Clin Pract 2010;16:1289-94.

4. Campbell S, Reeves D, Kontopantelis E, et al. Quality of primary care in England with the introduction of pay for performance. $N$ Engl $J$ Med 2007;357:181-90.

5. World Health Organization. Quality and accreditation in health services. A global review. Geneva, Switzerland: World Health Organization, 2003.

6. Deming EW. Out of crisis. Cambridge, MA: Massachusetts Institute of Technology, Centre for Advanced Engineering Study, 1986.

7. Buetow SA, Wellingham J. Accreditation of general practice: challenges and lessons. Qual Saf Health Care 2003;12:129-35.

8. Krankenversicherungsgesetz Schweiz. http://www.admin.ch/opc/de/ classified-compilation/19940073/201403010000/832.10.pdf (accessed 4 Nov 2014).

9. Kaderli R, Pfortenmueller CA, Businger AP. Healthcare quality management in Switzerland-a survey among providers. Swiss Med Wkly 2012;142:w13561.

10. Cassis I, Czerwenka W, Ramstein C, et al. [Qualität in der ambulanten Medizin: Zusammen ist man starker]. Schweizerische Ärztezeitung 2013;94:10 [in German].

11. EQUAM-Stiftung: http://www.equam.ch/de/ (accessed 4 Nov 2014).

12. van den Hombergh $P$, Grol R, van den Hoogen HJM, et al. Practice visits as a tool in quality improvement: acceptance and feasibility. Qual Health Care 1999;8:167-71.
13. Engels $\mathrm{Y}$, Dautzenberg M, Campbell S, et al. Testing a European set of indicators for the evaluation of the management of primary care practices. Fam Pract 2006;23:137-47.

14. Szecsenyi J, Campbell S, Broge B, et al. Effectiveness of a quality-improvement program in improving management of primary care practices. CMAJ 2011;183:E1326-33.

15. Götz K, Szecsenyi J, Broge B, et al. [Welche Wirkung hat Qualitätsmanagement in Arztpraxen? Ergebnisse aus Entwicklung und Evaluation des Europäischen Praxisassessments (EPA)] Göttingen: AQUA-Verlag, 2011 [in German].

16. Goetz K, Campbell SM, Broge B, et al. Effectiveness of a quality management program in dental care practices. BMC Oral Health 2014;14:41.

17. Schweizerische Akademie der Medizinischen Wissenschaften. [Zertifizierungen im medizinischen Kontext. Empfehlungen der Schweizerischen Akademie der Medizinischen Wissenschaften]. Muttenz, Basel: Schwabe, 2011 [in German].

18. Ogrinc G, Mooney SE, Estrada C, et al. The SQUIRE (Standards for QUality Improvement Reporting Excellence) guidelines for quality improvement reporting: explanation and elaboration. Qual Saf Health Care 2008;17(Suppl I):i13-32.

19. Schwappach D, Gehring K, Battaglia M, et al. Threats to patient safety in the primary care office: concerns of physicians and nurses. Swiss Med Wkly 2012;142:w13601.

20. Reader TW, Gillespie A, Roberts J. Patient complaints in healthcare systems: a systematic review and coding taxonomy. BMJ Qual Saf 2014;23:678-89.

21. Mandel D, Amital H, Zimlichman E, et al. Quality assessment program in primary care clinics: a tool for quality improvement. Int $J$ Qual Health Care 2004;16:175-80.

22. Vinker S, Lustman A, Elhayany A. Measurement of quality improvement in family practice over two-year period using electronic database quality indicators: retrospective cohort study from Israel. Croat Med J 2009:50:387-93.

23. Baker GR, Norton PG, Flintoft V, et al. The Canadian adverse events study: the incidence of adverse events among hospital patients in Canada. CMAJ 2004;170:1678-86.

24. Greenhalgh T, Heath I. Measuring quality in the therapeutic relationship. Part I: objectives approaches. Qual Saf Health Care 2010;19:475-8.

25. Rhydderch M, Edwards A, Elwyn G, et al. Organizational assessment in general practice: a systematic review and implications for quality improvement. J Eval Clin Pract 2005;11:366-78.

26. Miller $G$, Britt $H$, Pan $Y$, et al. Relationship between general practitioner certification and characteristics of care. Med Care 2004;42:770-8.

27. Petersen LE, Blackburn B, Puffer JC, et al. Family physicians' quality interventions and performance improvement for hypertension through maintenance of certification. J Healthc Qual 2014. Published Online First: 7 Aug 2014. doi:10.1111/jhq.12082

28. Grimshaw J, McAuley LM, Bero LA, et al. Systematic reviews of the effectiveness of quality improvement strategies and programmes. Qual Saf Health Care 2003;12:298-303. 